\title{
Stanislavski e a formação do ator
}

\author{
Stanislavski and the actor education
}

\section{Sérgio de Carvalho}

Sérgio de Carvalho Dramaturgo, diretor teatral e professor livre-docente da Universidade de São Paulo (USP)

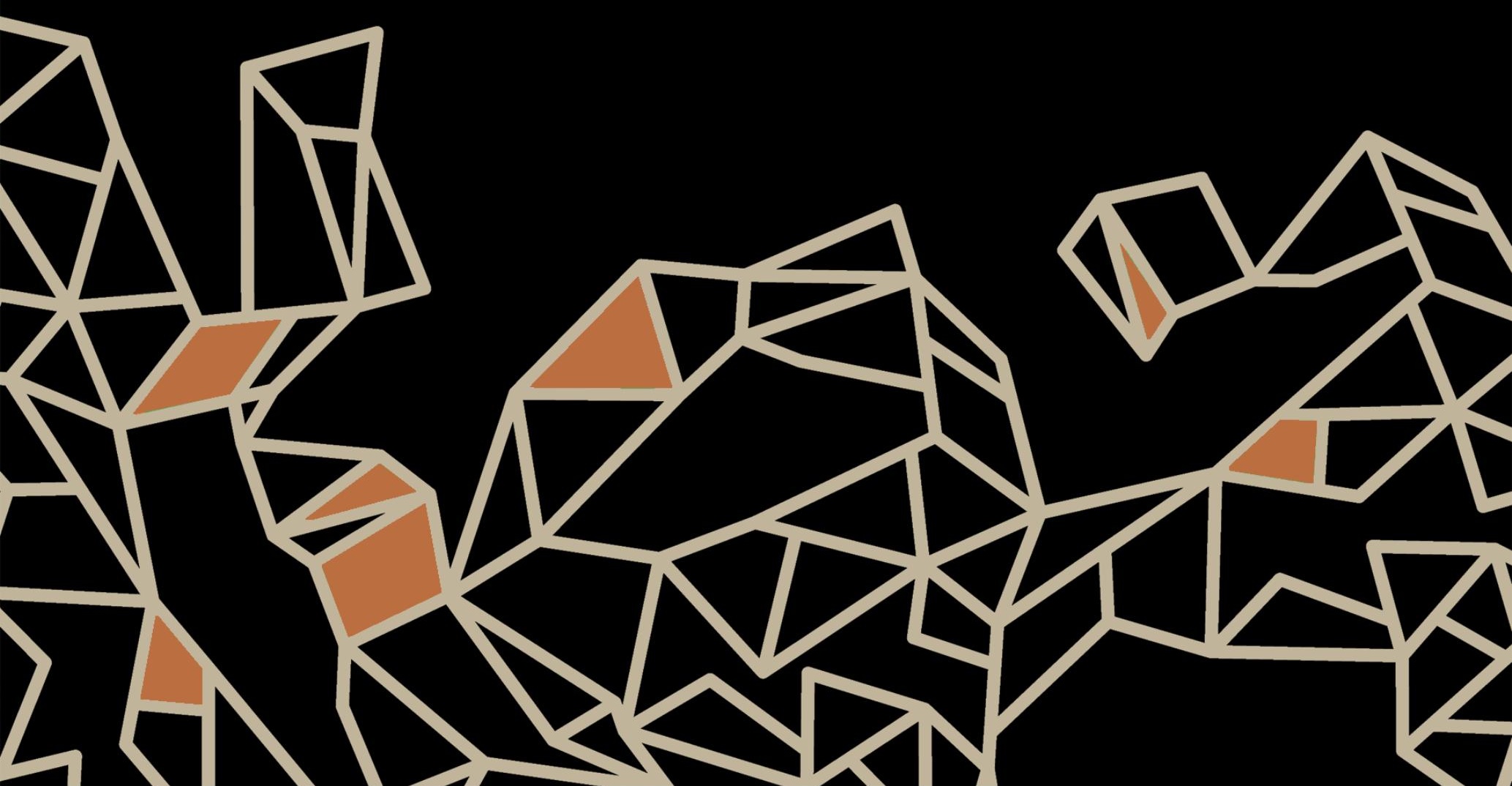




\section{Resumo}

O artigo examina os sentidos da ideia de formação no conjunto da prática pedagógica do diretor russo Constantin Stanislavski como uma procura de ativação de dinâmicas relacionais capazes de se contraporem à lógica do efeito estético e mercantil. A postura implica reflexões de sentido ético e mesmo político apenas lateralmente nomeadas em sua obra. Palavras-chave: Formação Cênica, Constantin Stanislavski, Efeito Estético.

\section{Abstract}

This article examines the meanings of the idea of education in the pedagogical practice of Russian director Constantin Stanislavski as a search for activation of relational dynamics capable of criticizing the logic of aesthetic and mercantile effect. Posture implies reflections of ethical and even political sense only laterally named in his work.

Keywords: Acting Education, Constantin Stanislavski, Aesthetic Effect.

As primeiras notas tomadas por Stanislavski com vistas a uma síntese literária de sua experiência teatral ocorrem uma década após a fundação do Teatro de Arte de Moscou. Por volta de 1909 ele começa a fazer uso da palavra "sistema" para designar a organização de alguns procedimentos que poderiam ser trabalhados por jovens atores que almejassem potencializar um "estado criador" comum aos grandes artistas do palco.

A convicção de que o teatro moderno exigia uma nova pedagogia teatral se traduz, a partir dali, na formulação de uma terminologia e de uma prática que deveria transcender à produção de espetáculos. Isso, evidentemente, esbarraria na realidade de uma companhia que àquela altura abandonara há tempos sua origem amadora e era então reconhecida como uma das mais importantes no desenvolvimento do Naturalismo europeu. Stanislavski, com vistas a elaborar seu Sistema, retoma, assim, a ideia de criar um estúdio livre, agora destinado à formação de jovens atores: fora do Teatro de Arte, mas conectado a ele. O empreendimento que efetivamente ocorre, tocado 
em conjunto com seu colaborador Sulierjitski, será mais tarde chamado de Primeiro Estúdio do Teatro de Arte, inspirando várias instituições similares.

Há tempos Stanislavski acreditava, a julgar por seus escritos pessoais, que a encenação moderna implicava uma nova formação. Ninguém estava pronto para a abertura de possibilidades gerada pelo estatuto artístico dado à cena. $\mathrm{O}$ ensaio havia se tornado um problema em aberto, as habilidades tradicionais se mostravam em crise e, por tendência de espírito, Stanislavski era reticente a qualquer experimentação que lhe parecesse de sentido puramente formal. Desde cedo, portanto, imagina o desenvolvimento dessa contradição entre encenação e um novo preparo artístico. Na medida em que suas preocupações não eram simplesmente técnicas, mas envolviam uma totalidade de operações, pode-se dizer que uma espécie de dialética da formação teatral passa a assumir o centro das preocupações de Stanislavski a partir de 1910, enquanto segue produzindo obras artísticas de estilos e gêneros diversos. $O$ ator haveria de passar por um processo de integração progressiva, verificando tensões a cada etapa cumprida. Dialética, porque o ideal de um estado criador, por mais que possa sugerir estabilidade, só poderia se dar num processo total:

[...] Era necessário estudar sistemática e praticamente durante anos, a vida inteira, constantemente transformando o concebido em habitual, deixando de pensar no assunto e esperando que ele se manifestasse de maneira natural, espontânea. Para isto era necessário o hábito, segunda natureza do artista, faziam-se necessários exercícios [...]. (STANISLAVSKI, 1989, p. 471)

Stanislavski pode ser considerado um exemplo notável daquilo que Peter Burger entende como desejo de "recondução da arte à práxis da vida" (BURGER, 2008, p. 17), projeto de vanguarda que será sempre contraditório e que alimentou a imaginação de tantos artistas da cena moderna.

Sua procura idealista de uma vitalidade natural, mesmo que também mediada por um cientificismo, contemporâneo ao esforço da psicanálise de sondar o inconsciente, era de fundo religioso e sua imagem de uma vivência plena das potências do teatro, rumo a um desenvolvimento das capacidades naturais da criação, tinha, em suas primeiras formulações, uma lógica iniciática, priorizando uma ascese que se dá do interior para o exterior. 
Por outro lado, seu compromisso radical com o raciocínio da formação, que pode ser lido como contribuição lúcida para que se supere o fracasso constitutivo de toda tentativa de arte transestética, era também uma crítica à mercantilização da vida, questão que mobilizou a geração naturalista.

\section{Encenação como práxis formativa}

O interesse na formação de um novo trabalho teatral já está na origem do Teatro de Arte de Moscou. Diante da nova dramaturgia, todo o aparelho teatral teria que se transformar: atores, práticas de ensaio, modos da sensibilidade artística, relação com o público.

No lendário jantar de 18 horas com Nemiróvich-Dánchenko, em junho de 1897, quando foram estabelecidas as premissas do Teatro de Arte, a ser inaugurado no ano seguinte, todas as críticas ao modelo oitocentista de teatro indicavam, para além da recusa ao convencionalismo, uma negação à lógica do efeito:

Nós protestávamos contra a velha maneira de representar, contra a teatralidade, contra o falso pathos, a declamação e a afetação cênica, contra o convencionalismo na montagem, as decorações e o estrelismo que prejudicava o conjunto, contra toda a estrutura dos espetáculos e o repertório deplorável dos teatros daquela época. (Ibid., p. 265)

Os primeiros espetáculos do Teatro de Arte na virada do século XIX para o XX (Czar Fiodor, de Alexei Tolstói, e A gaivota, de Tchekhov), ao mesmo tempo em que se pretendiam compromissados com um repertório russo elevado (outra dimensão da ideia de formação, neste caso a de uma literatura dramática nacional), logo se depararam com a dificuldade de superar as práticas convencionais, de abalar os esquematismos de um sistema teatral que se traduzia em hábitos inconscientes de ensaio.

Ali, Stanislavski percebeu que os problemas estéticos da modernização deveriam ser enfrentados do ângulo do trabalho, com gente como aquele grupo de estudantes e amadores que se mostravam provisoriamente dispostos ao trato experimental. Os próprios textos deflagravam as crises que se tornariam produtivas. Se Ibsen estava para o teatro inglês "assim como o xadrez está para o boxe", na sentença famosa de Bernard Shaw, um autor como 
Tchekhov, que o próprio Teatro de Arte avaliou como "não teatral", gerava dificuldades ainda maiores.

Ao abordar o problema do ponto de vista do encenador (no que divergia muito do parceiro Dánchenko, e aquelas montagens históricas são resultados desse conflito), Stanislavski entendia que a atuação deveria conter um sentido de verdade humana que todo o espaço também deveria expressar.

Aplicava, a rigor, a orientação naturalista do meio, fundada na interação entre a particularização interpretativa e o detalhismo ambiental. Seus espetáculos, assim, criavam ambientes com pormenores muito trabalhados. Eram extremados os cuidados com os figurinos (no caso de Czar Fiodor, peça histórica, usaram roupas de fato antigas, adquiridas no interior do país), adereços, com a passagem do tempo da ficção, que fazia uso de sonorização aclimatadora (os sons de grilos e sinos nas peças de Tchekhov). As mudanças do espaço-tempo já faziam uso criativo da iluminação e a angulação cenográfica, recortava criativamente quartos e salas, abrindo os interiores aos exteriores da casa. Em poucos anos o Teatro de Arte, avançando em relação ao projeto de Antoine, se torna referência de modernização pós-naturalista.

A particularização conceituada do trabalho também era influenciada pelos quadros históricos da companhia do duque Saxe-Meiningen, que excursionou pela Rússia na década anterior, muito conhecida pela excelência na composição das cenas coletivas, com vivacidade no conjunto de figurantes.

O Teatro de Arte de Moscou, na mesma direção, se empenha em superar o star system das velhas companhias e se notabiliza pelo conjunto cênico rico e inovador. Sendo o diretor um ator genial, tudo indica que Stanislavski fez uso, naquele momento, da própria capacidade imaginativa, oferecendo aos atores exemplos de como deveriam atuar. Chegava a desenhar marcas e gestos não convencionais para que fossem reproduzidos pelo elenco e detestava os velhos truques retóricos e a frontalidade grosseira que imperava nos palcos.

Suas primeiras direções, portanto, são exercícios de negação do velho teatro e decorrem da concepção avançada dos dois diretores da companhia. É assim que os intérpretes de Masha e Medvedenko em A gaivota entrarão em cena numa conversa sobre a cor das roupas e o luto "pela existência", desviando-se de galhos jogados no chão, girando gravetos, gestos sobrepostos aos previstos nas rubricas do texto (como aquele em que a moça cheira rapé). 
Esse atrito gestual nem sempre agradará a Tchekhov, mas importa dizer que o deslocamento das energias teatrais para a realidade física terá início ali como tendência poética.

Stanislavski condenava as abstratas exibições emocionais, as paixões genéricas. Queria indivíduos concretos, com especificidades, desejos intransferíveis. Ao mesmo tempo, sabia que a nova dramaturgia propunha caracteres em desajuste psíquico, o que pedia a criação de lapsos gestuais da ordem do inconsciente. A riqueza composicional dos protagonistas deveria aparecer na relação concreta com todas as figuras da história, como sugerem seus cadernos de direção daquela época.

Desde cedo, portanto, seu interesse poético era contrário a qualquer "demonstracionismo" orientado pela eficácia comunicacional. Os atores não deviam explicar nada ao público, ilustrar nada, exibir nada (muito menos a si próprios), mas sim viver a ficção da cena. Do ponto de vista do trabalho teatral, porém, as incríveis primeiras montagens do Teatro de Arte de Moscou ainda resolviam as questões estéticas de cima para baixo: a criação dos atores era dependente da imaginação criativa de um diretor genialmente obsessivo, o que não se dava sem grandes resistências.

Nos anos seguintes, em paralelo à montagem das peças realistas (muitas delas de temática social), o Teatro de Arte acompanha a tendência experimental lançada pelo Simbolismo, procurando ir além do "grosseiramente real". Stanislavski, nessas encenações, procura formas líricas e desenvolve uma "linha fantástica", impressionista ou grotesca (esse "gosto do tempo").

$O$ auge do processo de crítica, ao que lhe parecia então um desgaste do Naturalismo, foi a criação, junto com Meyerhold, seu discípulo mais politizado, do Estúdio da Rua Povarskaia. O experimento, tão importante como símbolo dos caminhos posteriores do teatro russo, não segue adiante pela desconfiança ciumenta do Teatro de Arte e pelo estouro da Revolução de 1905. Entretanto, confirma a Stanislavski a necessidade de ações na contramão da profissionalização da Companhia. Atividades formativas e laboratoriais, descomprometidas de resultados, eram imprescindíveis ao desenvolvimento de um teatro moderno.

O episódio revela, ainda, uma vontade de aprender com quem pensava diferente, de outra geração. Por outro lado, reforça a autocrítica em curso, que 
abre caminho para uma reflexão nova: o avanço da cena moderna, que se dava no plano espetacular e dramatúrgico, pouco atingia o trabalho dos atores: "E se essas descobertas forem o resultado de um simples entusiasmo, de uma ilusão? [...] E se tudo isto não vem de dentro, das vivencias internas, mas da vista e do ouvido, e da imitação externa das novas formas? [...]" (Ibid., p. 394).

Dirá, ainda, sobre os exercícios do Estúdio com Meyerhold: "O diretor de cena tentava encobrir com seu talento os artistas, que nas suas mãos eram simples argila para moldar grupos belos e mise-en-scènes, mediante as quais ele realizava suas ideias interessantes." (Ibid., p. 396).

Surgia uma convicção depois reincidente: o problema do elemento vivo e da verdade da cena não era questão de ordem estilística. Stanislavski intuía que a "falsidade" da imagem aparecia mesmo em cenas deliberadamente artificiais, em teatralidades estilizadas, não estando ligada à correspondência entre representante e representado. A mentira que atravessava as várias poéticas modernistas se relacionava com a atitude do artista para com seu trabalho.

$O$ auge desse processo de crítica em relação aos meios de produção do teatro se deu, segundo seu depoimento em Minha vida na arte, durante os ensaios da montagem de Hamlet, que iniciaram em 1909 e tiveram várias fases até sua estreia em 1912.

Gordon Craig, a quem Stanislavski considerava um "diretor de cena genial', idealizou uma cena que se mostrou muito à frente da realizada pelo Teatro de Arte, não obstante os inúmeros esforços da equipe. Na condição de preparador do elenco, Stanislavski avalia que "com os meios teatrais comuns, a interpretação estabelecida por Craig parecia no palco uma artimanha idealizada pelo diretor de cena, e só pela centésima vez nos convencia da impotência e grosseria dos meios cênicos que tínhamos à disposição" (Ibid., p. 463).

Não importava aí somente a verificação de um atraso ou o risco de converter um belo projeto numa obra menor. $E$ de fato não era só dos atores a dificuldade de realizar a elevação poética solicitada por aquele Hamlet. A crise expressa uma admiração pela capacidade de sonhar adiante: a utopia individual só seria real se toda a equipe fosse capaz de conquistar a mesma liberdade imaginativa. Enquanto não houvesse uma evolução conjunta, em que todos se tornassem agentes da cena, os descompassos não se resolveriam como forma estética elevada, permanecendo como ideal incerto. Para 
tanto, teria que ser traçado um caminho "de dentro para fora" dos meios da cena, com maior empenho criativo de cada ator, sem o qual seguiria valendo o princípio da reprodução. Numa carta ao conselho do Teatro de Arte, de 1910, ele já discute seu projeto: "Eu não quero só descobrir os princípios fundamentais do processo criativo, não quero só formular sua teoria, quero colocá-la em prática" (TAKEDA, 2003, p. 326).

Em meio ao idealismo de algumas das avaliações naquele momento, se confirma de vez para Stanislavski a exigência da formação. Ela era, no entanto, inesperadamente assemelhada à perspectiva materialista de superação do trabalho alienado. Sua motivação de fundo era uma espécie de reivindicação coletiva do direito à genialidade. $O$ ator não deveria ser nem um servidor da exterioridade do efeito mercantil, nem argila inanimada na mão da pesquisa alheia. O enfrentamento da coisificação, tema forte na cena naturalista, se infiltra nas reflexões de um artista que dedicava um culto quase religioso a seu ofício. O idealismo de uma frase como "não pense em você na arte, mas na Arte em você" se reverte, na prática coletiva dos ensaios, numa negação simbólica da forma-mercadoria, inadvertidamente afinada com as lutas sociais em curso na Rússia revolucionária. É nesse sentido que a procura do elemento vivo da cena, de sentido transestético, se liga, também em Stanislavski, a uma práxis de orientação antiburguesa.

\section{Romances de formação}

Nos anos que se seguem, Stanislavski se dedica a desenvolver e organizar seu Sistema para um novo trabalho teatral. Dividiu o plano de escrita de sua obra de acordo com quatro frentes, imaginando tratar de cada uma num volume separado. O trabalho que o ator pode realizar sobre si mesmo se desdobra em dois tomos, um relativo a aspectos internos, outro a externos. $O$ trabalho do ator em relação às personagens também geraria dois livros, conforme o deslocamento da ênfase, para o interior ou exterior da relação com a ficção.

Apesar da separação didática, que não chegou a ser cumprida, cada fragmento de sua escrita deveria conter uma pedagogia, uma exposição técnica - de fins estéticos e psíquicos -, uma ética. O que projeta, por sua vez, dimensões religiosas, científicas e políticas. Ele produziu, assim, não uma poética didática, 
mas uma espécie de romance de formação no estilo iluminista do século XVIII, em que seu ponto de vista oscila entre o professor e seus alunos de teatro. Concebeu uma obra entre a ficção e o documento que exigiria, a rigor, uma experimentação prática, ou mais do que isso, uma vivência, para ser compreendida.

A difícil recepção desse legado ao longo do século $X X$ e sua frequente incorporação rebaixada por teatros conservadores e pela indústria cultural liga-se a vários fatores. Após a Revolução Russa, Stanislavski foi associado, devido a razões circunstanciais, à herança de uma cena burguesa progressista do passado. E, mais tarde, a um Realismo socialista estalinista. Os dois equívocos transmitem a imagem de um legado edificante. A própria forma setecentista de seus livros reforça a imagem de um classicismo epigonal, da ordem do conhecimento positivo, e não do mundo do trabalho.

A difusão internacional do primeiro dos quatro volumes redigidos (conhecido no Brasil como A preparação do ator), na versão editada de Elizabeth Hapgood, ajudou a solidificar a imagem de um método teatral psicologista. Isso ocorreu não só pelo destaque que o primeiro livro teve em relação aos outros, mas por sua pronta associação ao desenvolvimento que alguns de seus princípios obtiveram em território norte-americano, confirmados pela prática de Richard Bolelavski, um dos colaboradores do Primeiro Estúdio do Teatro de Arte, que em seu exílio nos Estados Unidos muito influenciou Lee Strasberg e a geração do Actor's Studio, fundado por Kazan e Lewis.

Bolelavski acompanhou as primeiras experiências de Stanislavski na pedagogia do estado criador. E naquele momento as experiências se voltavam ao desmonte dos condicionamentos psicofísicos que envolvem uma atividade, a atuação, que sempre comportará a dupla tarefa da criação simbólica e de sua transmissão comunicacional. Stanislavski acreditava que "a criação é acima de tudo a plena concentração de toda a natureza espiritual e física" (STANISLAVSKI, Op. cit., p. 414).

A capacidade de concentração implicava, contudo, uma série de operações, entre as quais a definição precisa dos "círculos de atenção" e a superação do "medo da boca de cena". O apelo a analogias extraídas da "memória emotiva", aspecto depois tão enfatizado nas vulgatas stanislavskianas, é um entre vários recursos de desenvolvimento daquilo que nunca deixou de ser crucial em sua visão de teatro, a imaginação. 
A libertação criativa pessoal - dependente do exercício diário desse "músculo" chamado imaginação - se associava à capacidade simbólica de se tornar outro: era a alteridade o que interessava, a diferença conquistada por uma relação imaginária materializada no corpo, não o ensimesmamento psíquico. A concentração criativa advinha, assim, de conseguir orientar "a natureza espiritual e física" para o que "ocorre ou pode ocorrer na alma do personagem que está sendo representado" (Ibid., p. 414).

Nos anos seguintes, após a Revolução, novos acontecimentos influem nas reflexões de Stanislavski em relação ao trabalho do ator. A experiência de trabalho com os cantores do Estúdio de Ópera do Teatro Bolshoi faz que ele se dedique a pensar nas possibilidades de um "bom convencionalismo" e reorganize seu aprendizado em relação ao treinamento dos meios expressivos, aspectos necessários para que a beleza da interpretação se manifeste, como a plasticidade do movimento, a dicção, e, sobretudo, o tempo-ritmo da cena. Qualquer construção imaginária pode se converter numa estática se não mobilizar a consciência dos próprios e diversos tempos-ritmos. Essas questões serão associadas por ele à dimensão exterior do trabalho do ator sobre si (apontadas no volume conhecido no Brasil como A construção da personagem).

Do ponto de vista da evolução do Sistema, entretanto, sua prática reforça uma impressão sempre evidente no teatro: qualquer ator terá muito mais facilidade de desempenhar tarefas de ordem física do que de ordem imaginária, sempre resolverá de modo mais prazeroso problemas concretos do que abstratos, daí um recorrente descalibramento formativo que reforça as expectativas mercantis: são muitos os intérpretes com grande consciência vocal ou corporal, eficazes na comunicação com o público, mas opacos quando se trata de uma "vivência" ficcional sincera, porque incapazes de imaginar. Stanislavski começa a perceber que o caminho do estado criativo não precisa ser trilhado, necessariamente, desde a interioridade do artista.

\section{Método das Ações Físicas}

Nos últimos anos da década de 1920 essa percepção se expande a ponto de abalar o próprio ideal de Sistema. Opera-se uma inversão metodológica. Ele passa a criticar os próprios métodos antigos de direção: 
Lembre-se que as mises en scène de $A$ gaivota foram realizadas pelos métodos antigos, agora completamente rejeitados, de imposição das emoções pessoais sobre o ator, e não pelo método de estudar em primeiro lugar o ator - suas capacidades, o material de sua personagem, antes de criar a mise en scène apropriada e deseja. Em outras palavras, o método das antigas mises en scène pertence ao diretor despótico que eu agora combato, enquanto as novas mises en scène são feitas por diretores que dependem do ator. (TAKEDA, Op. cit., p. 355)

É provável que algo da perspectiva materialista, tão convocada pela cultura do tempo, inspire a guinada em curso. Mas a verdade é que a nova fase radicaliza uma dialética da formação anterior, orientada pela procura de relações de trabalho cada vez mais vivas.

Não pretendendo "outro sistema" - feito antes de princípios para a ação teatral coletiva -, o assim chamado Método das Ações Físicas que surgiria a partir dali invertia qualquer abordagem convencional do teatro. Não se tratava mais de reunir especialidades em torno do estudo de um texto e materializar uma ideia. O que se pretendia era um estudo prático, físico, fundado na superação, mesmo que provisória, das especializações, com vistas a uma invenção partilhada.

No trabalho com ações físicas, o processo interpretativo não percorre mais as etapas convencionais, da leitura de mesa, definição de plano cênico, o ensaio, marcação no espaço. Os atores terão seu primeiro contato com a ficção através das improvisações. Mesmo quando há uma peça pronta, ela deve ser analisada ativamente, isto é, deve ser improvisada pela equipe com base nos acontecimentos mais concretos que definem a fábula. Esses acontecimentos serão transmitidos pelo diretor, que se abre, assim, a repercorrer o caminho gerativo da dramaturgia.

É uma pesquisa física, porque atenta, em seu início, às relações gestuais da história, o que antecede as posteriores análises das palavras da peça. É preciso constituir o processo das relações ficcionais, antes de que qualquer forma verbal se fixe em seus ritmos. A imaginação deixa de ser, assim, uma produção individual. Será o grupo que fortalecerá de modo prático sua vivência imaginária, mobilizando o "espírito" da ficção, antes que a letra das formas cênicas se estabilize. Começa-se pelo começo, aquilo que está antes do texto, o mundo por trás das relações verbais. Em certo sentido, todos se tornam dramaturgos. 
O princípio da formação é como que internalizado: o ensaio se dá por meio de estúdios, o processo deve ser o estimulado, não a procura do resultado.

As principais descrições dessa nova perspectiva de trabalho não foram redigidas por Stanislavski. Apesar de ter deixado ótimos textos sobre ações físicas (parte deles reunidas no volume $A$ construção da personagem), há mais elementos para compreender o alcance da proposta nos livros de discípulos como Gorchakov, Toporkov e Maria Knebel.

São muitos os pontos experimentados por Stanislavski nesses primeiros anos da década de 1930, quando se dedicou intensamente a compreender essa possibilidade formativa. Continuavam válidos os pontos fundamentais no desenvolvimento da capacidade de viver a ficção e comunicá-la ao público, mas o centro do Sistema, o se mágico ("e se eu estivesse na mesma situação, diante das mesmas circunstâncias, como me comportaria?"), isto é, o imaginar-se outro a partir do mesmo, se torna dinâmico: não é mais um ideal do ator, mas uma prática que se modifica todos os dias, feita por toda a equipe, em torno de um estudo. Tudo aquilo que é necessário para a conquista do chamado "círculo de solidão pública" - concentração, calma, domínio técnico do próprio instrumento, imaginação concretizadora - passa a ser aprendizado comum, balizado pela atitude interessada diante da ficção.

É por isso que os discípulos de Stanislavski tanto enfatizam que o trabalho com ações físicas deve iniciar por um esforço de objetivação, como informa Maria Knebel:

Stanislavski achava que o plano mais acessível para a análise através da ação era o dos fatos, dos acontecimentos, ou seja, o da fábula da peça. Por isso propunha começar a análise sistemática da peça com a definição dos acontecimentos ou, como dizia às vezes, dos fatos ativos, de sua sequência e interação. (KNEBEL, 2016, p. 131)

As muitas estratégias que decorrem daí só podem ser entendidas na prática. Refutam a imagem psicologista que acompanha Stanislavski. O Método das Ações Físicas nega a possibilidade de que qualquer emoção possa ser "representada" no teatro. O falso pathos se liga à tentativa de sentimentalizar e subjetivar tudo através da incorporação de estados emotivos, o que conduz antes à exposição da própria falsa consciência do que à concretização 
da emoção. Um ator estará sempre mentindo ao representar uma emoção, mas não vai mentir quando tentar realizar uma ação capaz de despertar uma emoção. A comoção deixa de ser um fundamento da cena e passa a ser uma possível consequência de interações gestuais. A ação física correta, na circunstância correta, pode suscitar dinâmicas emocionais partilhadas, para além da expressão (paradoxalmente cerebral) de estados afetivos.

\section{Formação relacional}

O Método das Ações Físicas sugere, portanto, que o trabalho teatral deve ocorrer como formação partilhada, como estúdio, como paixão pela atividade. Sua amplitude estilística é enorme, indo muito além do realismo, a ponto de muitos artistas de tendências diferentes terem se interessado por suas proposições. Stanislavski procurou destacar esse ponto, mostrando a força do Método no trabalho dos textos clássicos, diante dos quais a análise ativa seria apenas uma primeira parte de um trabalho que envolve também a pesquisa de ações verbais, de ritmos plásticos, de formalizações esteticamente vivas.

Apesar das grandes possibilidades que o princípio oferece, ele também dá margem a muitos equívocos, sobretudo após sua reintrodução nos debates teatrais a partir da década de 1980, quando a leitura pulsional do conceito de Ação Física, feita por Grotowski (em seus últimos anos de trabalho ele combinava ações físicas a cantos vibratórios na procura de estados alterados de consciência do ator) passou a sugerir que se tratava de uma técnica de expansão das energias presenciais da atuação. $O$ desdobramento disso nas reflexões de Eugênio Barba, interessado na Ação Física como a menor ação perceptível que se reconhece pela "mudança de tonicidade" do corpo, já indica uma adulteração do conceito ainda maior: passa a ser uma medida estrutural, com vistas a efeitos na recepção.

A verdade é que Stanislavski entendia Ações Físicas como um conceito relacional. O que importa é a relação concreta estabelecida entre a ação do ator e a dos outros atores em face dos acontecimentos. Dessa perspectiva, relações físicas serão, também, sempre relações psicofísicas, pois no teatro nunca se pode "interpretar a própria presença". 
Toporkov é muito claro quanto às prioridades do Método:

Transferir a atenção do ator da busca da emoção interna para a realização de uma tarefa cênica é uma das grandes descobertas de K. S. Stanislávski, que resolve um dos grandes problemas de nossa técnica. [...] Excluiu as possibilidades de que o ator se enamorasse de seus próprios sentimentos e mostrou o mais fiel, o único caminho à revelação das emoções humanas autênticas no ator, direcionadas para a realização de uma tarefa cênica que aja diretamente sobre o parceiro. (TOPORKOV, 2016, p. 54, grifo nosso)

A dificuldade em extrair forças da relação de alteridade é o que torna as ações simples do cotidiano as mais difíceis de serem representadas. O mesmo ator que consegue vivenciar os conflitos das paixões lancinantes ou recitar um monólogo confessional terá dificuldade em simplesmente abrir uma porta e pedir a alguém que abandone a sala, em parte por rejeição ao prosaísmo da ação banal, mas sobretudo pela real dificuldade em atuar no aqui e agora da relação voltada ao outro.

Porque toda técnica serve a uma visão de mundo, o projeto teatral stanislavskiano deve ser compreendido dentro das coordenadas de um grande realismo teatral - o que significou um campo estilístico vasto na medida em que o ideal de busca de uma verdade do trabalho ultrapassava qualquer interesse na reprodução da aparência do real empírico. A disposição à alteridade apontada por sua pesquisa é ferramenta que contribui para a complexificação de qualquer teatro ainda hoje animado pela alegria do impulso mimético.

Nos últimos anos de vida, o alemão Bertolt Brecht, movido em parte pelo fato de estar vivendo na Alemanha Oriental de influência soviética, revê sua crítica feita anos antes a Stanislavski. Após a leitura de obras como a de Gorchakov, ele percebe a dimensão de uma formação negativa expressa nos conceitos do velho professor a seus atores: 0 ator que representa um bêbado no palco não deve mostrar a volubilidade e a voz pastosa, mas sim os esforços para parecer sóbrio e caminhar em linha reta; o ator que representa o homem mesquinho, deve mostrar os esforços para parecer generoso; não representar a raiva, mas a tentativa de controlá-la etc.

A dialética da ação decorre de sua interação contraditória. É preciso mover-se pelas forças em luta, que são internas e externas - como dizia Mao Tsé-Tung. A noção de que não interessa representar o estado (a tristeza do 
choro), mas o esforço para escondê-lo, significa que um "outro alguém" também move a cena, com suas próprias contradições. O movimento simbólico é, portanto, sempre negativo: só age quem realiza o negativo da ação.

O Método das Ações Físicas serve, portanto, perfeitamente ao teatro dialético de Brecht, desde que a qualidade da supertarefa (ou superobjetivo) seja estabelecida como crítica sócio-histórica, desde que a compreensão da linha de ação transversal da fábula expanda as contradições para todos os níveis da cena. Brecht não suportava "senão a contradição", mas aquelas de ordem mais subjetiva deveriam estar implicadas nas contradições sociais e de classe.

Ainda hoje, a exigência de uma aposta nos processos vivos é o que torna o Método de Stanislavski tão difícil e tão bonito.

\section{Imaginação coletiva}

Seria preciso, ainda, lembrar que parte do idealismo retórico que tanto atrapalhou o uso das invenções de Stanislavski também se conecta ao fato de que ele procurou configurar uma ética à antiga, feita de lições e exemplos. Era preciso atuar no todo e a dimensão estética só fazia sentido como atitude moralmente consequente.

Não são poucos os discursos do velho professor sobre a necessidade de responsabilidade para com a equipe; atrasos, as roupas que o ator lança ao chão, quando, após o fechar das cortinas corre para o camarim para se livrar da maquiagem e receber os amigos; sobre o coquetismo dos que flertam com o público; a preocupação em agradar a opinião alheia; sobre a vaidade, mesquinharia e inveja nos ensaios; a expectativa fútil de protagonismo; a subserviência a quem julga ser uma figura importante; sobre tudo aquilo que mina o bom ambiente teatral. Parecem banais, mas são percepções decisivas: como esperar criação livre onde a disputa mercantil e a miséria da consciência se impõem até nas relações mais íntimas?

O que parecia antigo, entretanto, era novo. Por estar voltada às relações de trabalho, por subverter minimamente a divisão entre trabalho braçal e intelectual, sua ética, mesmo sem enfrentar a questão da luta de classes, surge como simbolismo político. Estava em causa, também para Stanislavski, uma produtividade mais igualitária. 
E se a própria Revolução Russa não foi capaz de pôr abaixo a disposição geral dos artistas à venalidade, às dinâmicas culturais voltada para a troca, o que dizer do projeto de Stanislavski hoje, tempos em que a mercantilização não soa mais como problema, mas parece, antes, ser a solução ardentemente desejada?

$\mathrm{O}$ ator mau caráter era fundamentalmente aquele sem interesse real pela vida dos outros, o que jamais tocaria o coração da relação ética - a preocupação com o sofrimento alheio. A nova prática haveria de ser mais eficaz do que os velhos conselhos, mas a atividade criativa e a arte da improvisação dependem de um bom ambiente, da confiança nas pequenas ações provisórias. São elas que conduzem a novas ações conjuntas. $O$ simbolismo emancipatório se dá nesse movimento, de consciência que o teatro é uma pequena parte do mundo, de imaginação coletiva rumo ao melhor possível. Stanislavski disse certa vez que se os teatros fossem verdadeiramente lugares de arte, deveriam trazer escrito, na fachada, uma divisa como a seguinte: mais simples, mais claro, mais animado, mais alegre.

\section{Referências bibliográficas}

BURGER, P. Teoria da vanguarda. Tradução José Pedro Antunes. São Paulo: Cosac Naify, 2008.

CARVALHO, S. Um trabalho com Stanislavski. In: PIACENTINI, N.; FÁVARI, P. (org.) Stanislavski revivido. São Paulo: Giostri, 2014. p. 28-34.

CARVALHO, S. Stanislavski, um século em cena. Bravo!, [S. I.], ano 1, n. 8, p. 116119, 1998.

KNEBEL, M. Análise-ação: prática das ideias teatrais de Stanislavski. Tradução Marina Tenório e Diego Moschkovich. São Paulo: Editora 34, 2016.

STANISLAVSKI, K. Minha vida na arte. Tradução Paulo Bezerra. Rio de Janeiro: Civilização Brasileira, 1989.

TAKEDA, C. L. (org.). Cotidiano de uma Lenda: cartas do Teatro de Arte de Moscou. São Paulo: Perspectiva, 2003.

TOPORKOV, V. Stanislavski ensaia: memórias. Tradução Diego Moschkovich. São Paulo: É Realizações, 2016.

Recebido em 17/07/2019 Aprovado em 19/07/2019

Publicado em 30/08/2019 